\title{
Factors affecting Cloud Computing adoption in Higher Learning Institutions in South Africa: A case of Matjhabeng TVET Colleges
}

\author{
Dina Moloja ${ }^{1,2}$, Ephias Ruhode ${ }^{2}$ \\ ${ }^{1}$ Faculty of Engineering, Built Environment and Information Technology,Central University \\ of Technology, South Africa, ${ }^{2}$ Faculty of Informatics And Design, Cape Peninsula University \\ of Technology, South Africa.
}

\begin{abstract}
Cloud Computing is one of the most important trends and newest area in the field of information technology in which resources (e.g. CPU and storage) can be leased and released by customers through the Internet in an on-demand basis. The adoption of Cloud Computing in Higher Learning Institution is a real opportunity. Although Cloud computing has gained popularity in the world especially in education and industry, but its impact in colleges is still unexplored. This exploratory qualitative research seeks to identify the factors affecting the adoption of Cloud Computing in South Africa, focusing on Matjhabeng TVET colleges. 35 IT stakeholders from two TVET colleges was interviewed. Thematic analysis was utilised to analase data. After data was analysed, the findings revealed that data security, lack of internet access and lack of infrastructure resources are key factors that affects Cloud computing adoption in Matjhabeng TVET colleges. This paper contributes to the literature on Cloud Computing adoption in Higher Learning Institutions in South Africa.
\end{abstract}

Keywords: Cloud Computing; Higher Learning Institutions; Information and communication Technology; Adoption. 


\section{Introduction}

Higher Learning Institutions (HLIs) in South Africa (SA) and across the world are in the historic era. Information Technology (IT) abilities are said to be significant cost centres to many promoters, even though an institution relies on technology in every aspect of its operation, it is difficult to perfectly calculate the return-on-investment (ROI) from the cost of information technology. Similarly, it is challenging to attribute the benefits of technology in a straight line to the institution's vision, mission and goals. An innovative technology that promises cost saving and better service delivery for any organization is Cloud Computing (CC) (Alharbi, Atkins \& Stanier, 2016; Tarig, Tayyaba, Rasheed \& Ashraf, 2017; Krauss \& Va der Schyff, 2014).

Cloud computing is a rapidly evolving model that enables institutions to access computing resources as a service directly over the Internet (Almajalid, 2017). This model is radically different from current on-premise deployment strategies in part because it shifts the burden of owning (licensing) and operating (support and maintenance) the often complex computing environment to a third party called a cloud service provider (CSP) (Gangwar \& Ramaswamy, 2015). Currently, the public higher education sector in South Africa is composed of 26 public universities and 50 technical and vocational education and Training (TVET) colleges spread across the country's nine administrative provinces (Krauss \& Va der Schyff, 2014; Le Roux $\&$ Evans, 2011). Adopting the cloud computing model for selected tasks can bring huge benefits to these institutions. For example, sharing resources such as expensive hardware, software and technical expertise can significantly lower the overall IT costs because available resources are better utilized and delivery costs can be shared among multiple institutions (van Biljon \& van der Merwe, 2018).

Cloud computing may also make it easier for smaller colleges and universities with limited resources and in-house capacity to gain access to cutting edge IT resources that they would otherwise not be able to procure and operate on their own (Ali, 2018; Almajalid, 2017). A further argument is that public universities and colleges share many similar operational processes such as course offerings, admissions, enrolments, bursaries, research and graduations that can be standardized across the higher education sector, and offered as a set of services to the many colleges and universities in a more cost effective way than is currently the case (Akin, Matthew \& Comfort, 2014; Seke, 2015). Granted, cloud computing is not without its challenges and risks, but it is argued here that its benefits and opportunities far outweigh the risks. Even as cloud computing continues to make inroads into South African Universities, its adoption in South African colleges remain unclear (Krauss \& Va der Schyff, 2014; Le Roux \& Evans, 2011).

This paper uses semi structured interviews to identify the factors that affects CC adoption in HLIs in SA, specifically at Matjhabeng TVET colleges. The paper is organized as follows: 
section 2 presents the literature review; In section 3, the state of art in Matjhabeng TVET colleges is asserted. Research methodology is presented in section 4. Section 5 reports the research findings. The limitations of this paper are stressed in section 6 . The paper concludes with recommendations in section 7 .

\section{Literature Review}

The conceptual, logical and architectural development over Networking, Internet and Grid computing has given birth to the third (3rd) technological revolution after Personal Computer (PC) and the internet known as cloud computing (Alharbi et al, 2016; Olabiyisi, Fagbola \& Babatunde (2012). Cloud computing can be described as a composite three-tier delivery, development and application platform . As a delivery platform, it uses an on-demand cloudbased infrastructure to deploy an infrastructure or applications, for example, the Amazon Elastic Cloud (Saidhbi, 2012).

The on-demand cloud-based development environment provides a general purpose programming language (for example, Bungee Labs, Coghead, google sites) as a development platform. As an application platform, it is used to develop and deploy end-user applications (for example, Salesforce.com, NetSuite, Cisco-WebEx and google docs).

Ali (2018) defined cloud computing as an elastic and scalable utility model that offers flexible, ubiquitous, on-demand network access to a shared pool of configurable computing resources (for example, servers, data centers, networks, applications and services) that can be rapidly provided and released with limited interaction of service provider or the management. It provides shared infrastructure, self-service, dynamic and virtualized pay-peruse platforms which put it on high demand. Cloud computing implies a level of dynamic, flexible resource sharing and allocation of assets.

Matthew (2015) conducted interview with a panel of the world's top technologists discussing new technologies changing higher education especially "education in the cloud" trend. Shel Waggener, the senior vice president of Internet and former Chief Information Officer (CIO) at University of California in Berkeley, Ted Dodds, Chief Information Officer and Vice President at Cornell University, Ron Kraemer, the vice president and CIO at Notre Dame University and Bill Wrobleski, Director of infrastructure services for information and technology services at University of Michigan discussed issues relative to benefits of cloud adoption, risk factors and risk management practices. A great number of advantages of using cloud computing in education were highlighted and techniques for mitigating the risk of cloud adoption were explained.

Seke (2015) conducted a survey on the adoption of cloud computing among public universities and FET colleges within Africa. The authors argued that public universities and 
colleges share many similar operational processes such as course offerings, admissions, enrollments, bursaries, research and graduations that can be standardized across the higher education sector and offered as a set of services through cloud to the many colleges and universities in a more cost effective way than is currently the case. The results of the analysis shed some light on the current state of cloud computing adoption within the South African public higher education sector, the main factors that fuel its adoption, the main barriers that impede its adoption and the direction it may take in future as it matures.

Akin et al. (2014) argued that cloud computing is the solution to ICT in higher education in Nigeria. The authors identified scarcity of ICT infrastructure and lack of access, high cost of ownership, unsteady and inadequate electrical power supply as factors that are limiting the infusion of ICT in Nigeria higher education. They claimed that the prospect of a maturing cloud of on-demand infrastructure, application and support services is important as a possible means of driving down the capital and total costs of ICT in higher education, facilitating the transparent matching of IT demand, scaling ICT, fostering further ICT standardization and accelerating time to market by reducing ICT supply bottlenecks.

\section{The state of art at Matjhabeng TVET colleges}

South Africa as a developing nation has suffered by limitation of educational budgets. HEIs are being builtin very high speed. Currently there are around 26 government owned universities and many private colleges. Without quality education establishing educational institutions by itself cannot give the solution we seek for economic development and poverty reduction through education. Education should be supported through up to date technologies and services. Ethiopian government has been investing millions of dollars every year to support education in higher education institutions with technology. However due to struggling economy it is not able to supply full ICT infrastructure requirements of all universities.

Currently, colleges in Matjhabeng are still utilizing a paper notice board to communicate with the students. The method of communication is not efficient as students needs to be on campus premises to access available notices. Furthermore, their IT services is still locally managed which requires constant maitainance and upgrade.

\section{Research Methodology}

This research is an exploratory qualitative based study. Semi-structured interviews were utilised to collect primary data. Open-ended questions were asked to respondent in order to capture qualitative data. 


\subsection{Population and Sample}

The target population are Higher learning Institution in South Africa that have some experience of using a cloud solution and its benefits. Based on the literature that the researcher reviewed, some South African Universities have already adopted and used CC in the past, University of Cape Town and University of Pretoria. However, these two Universities have adopted some of CC serves and models not all of them. After observing other HLIs, there was another University in the Free State that have recently adopted the cloud, and no previous case studies for TVET colleges in SA. Therefore, this research interviewed 35 TVET college stakeholders. All the interviews were recorded and varied between 45 to 60 minutes each. Since there are limited case studies in the South African context, the previous South African Universities on cloud computing were compared to the results discovered in this paper in order to discover the factors that affect the adoption of $\mathrm{CC}$ in Matjhabeng TVET colleges in SA. With respect to ethics, the respondent's names were kept anonymous and were referred to as alternative pseudonyms e.g. respondent 1 .

\subsection{Data collection}

HLIs in SA represent the research population. The sample of the research was also drawn. Olabiyisi et al. (2012) states that HLIs are considered a potential customer or consumer of cloud services as opposed to an actual vendor. The data collection tool was semi-structured interviews. The student interviews were conducted in a private room on-campus. A total of 35 interviews were conducted (out of an initial sample of 40 ), thus yielding an $88 \%$ response rate. Five interviewees failed to turn up for the interview. Therefore, a total of 35 valid responses were analysed.

\subsection{Data Analysis}

Thematic analysis was used to analyse the research data. Following verbatim transcription, the data was analysed. Descriptive accounts of the research data were presented and the most significant findings were deduced.

\section{Research Findings}

A thematic analysis of each variable was carried out to measure the responses of the participants in the factors that affect CC adoption in SA. During the interviews, the researcher discover that there are many factors that affect the adoption of CC in HLIs in SA. The table below mentions few of them: 
Table 1: Factors affecting the adoption of Cloud Computing in Matjhabeng TVET colleges

\begin{tabular}{l}
\hline Data security \\
Poor internet access \\
Infrastructure \\
Insufficient skilled staff \\
Government support \\
Socio economic status \\
Poor Internet access \\
Confidentiality \\
Complexity \\
Affordability \\
Privacy
\end{tabular}

Based on the above discovered factors, $62.4 \%$ of the respondence stated that data security, poor internet access and infrastructure are key factors affecting $\mathrm{CC}$ adoption because South Africa is one of the developing countries with limited computational resources. $26.5 \%$ of the respodence asserted that insufficient skilled staff, government support and socio economic status are another factors that affect $\mathrm{CC}$ adoption. Confidentiality, Complexity, Affordability and privacy were highlighted by $11.1 \%$ of the respondents.

\section{Research Limitations}

There is a limited research articles in South African context on CC adoption in HLIs hence the researcher had to review other research papers on CC adoption in HLIs from other Countries like Kenya, Nigeria, Ethopia and Pakistan.

\section{Conclusion and recommendations}

In this paper, we identified influential factors in the adoption of cloud computing in HLIs in SAbased on existing literature and opinions of the expert in IT. The paper demonstrated the factors that are affecting the adoption of CC in SA, focusing on Matjhabeng TVET colleges. Subsequently, The authors have shown that the purpose of a university or college does not necessarily allow for any generalizations to be made; that adoption in CC can be viewed as either internal or external to the University; that stakeholders often make judgements about 
whether cloud services can be trusted based on how it is evaluated and the negative views associated with data security, lack of infrastructure and limited internet access. The inductive nature of the work has specific benefits in terms of relevance. It shows an authentic account of locally contextualized events and a knowledge construction approach that can amplify existing knowledge on adoption issues in HLIs in SA.

Although this study is limited to a small number of participating TVET colleges as well as being averse to specic cloud technologies and vendors, it still provides future researchers with the concepts, and recommendations for further work. It is anticipated that further work would uncover even more detailed concepts which could either directly or indirectly aect cloud adoption. Further limitations include that this study only focused on IT professionals within two types of South African colleges and did not include any participants from academia. Views expressed in this paper should therefore be seen in an operational light, with few considerations on the challenges by academic departments themselves. The contextsensitive nature of this study also limits the generalizability of its results to other situations.

In future, the factors that are discovered in this paper can be utilised to pave a way for a conceptual frame work that can highlight factors to be considered when adopting CC in HLIs in SA. Further research can be undertaken to explore more factors and issues that influence the adoption of CC in HLIs. In addition, it would also be stimulating to explore data security enhancing factors from the cloud computing service provider's perspective.

\section{References}

Akin, O. C., Matthew, F., \& Comfort, D. (2014). The impact and challenges of cloud computing adoption on public universities in Southwestern Nigeria. International Journal of Advanced Computer Science and Applications, 5(8), pp.13-19.

Alharbi, F., Atkins, A., \& Stanier, C. (2016). Understanding the determinants of Cloud Computing adoption in Saudi healthcare organisations. Complex \& Intelligent Systems, 2(3), pp.155-171.

Ali, M. (2018). The Barriers and Enablers of the Educational Cloud: A Doctoral Student Perspective. Open Journal of Business and Management, 7(1), pp.1-24.

Almajalid, R. (2017). A survey on the adoption of cloud computing in education sector. arXiv preprint arXiv:1706.01136.

Gangwar, H., Date, H., \& Ramaswamy, R. (2015). Understanding determinants of cloud computing adoption using an integrated TAM-TOE model. Journal of Enterprise Information Management.

Krauss, K. E., \& Van der Schyff, K. (2014). Higher education cloud computing in South Africa: towards understanding trust and adoption issues. South African Computer Journal, 55(1), pp. 40-55.

Le Roux, C. J. B., \& Evans, N. (2011). Can cloud computing bridge the digital divide in South African secondary education?. Information development, 27(2), pp.109-116. 
Matthew, F. T. (2015). Cloud Computing In Education-A Study of Trends, Challenges and an Archetype for Ef-fective Adoption in Nigerian Universities. Information communication technology (ICT) integration to educational curricula: a new direction for Africa, pp. 119.

Saidhbi, S. (2012). A cloud computing framework for Ethiopian Higher Education Institutions. IOSR Journal of Computer engineering, 6(6), pp.01-09.

Seke, M. M. (2015). Higher education and the adoption of cloud computing technology in Africa. International Journal on Communications, 4(0), pp.1.

Tariq, M. I., Tayyaba, S., Rasheed, H., \& Ashraf, M. W. (2017, March). Factors influencing the Cloud Computing adoption in Higher Education Institutions of Punjab, Pakistan. In 2017 International Conference on Communication, Computing and Digital Systems (C-CODE) (pp. 179-184). IEEE.

Olabiyisi, S. O., Fagbola, T. M., \& Babatunde, R. S. (2012). An Exploratory Study of Cloud and Ubiquitous Computing Systems. World Journal of Engineering and Pure \& Applied Sciences, 2(5), pp.148.

van Biljon, J., \& van der Merwe, R. (2018, March). Trends, drivers and barriers influencing cloud computing services for mobile interactions in teaching and learning. In 2018 Conference on Information Communications Technology and Society (ICTAS) (pp. 1-7). IEEE. 